$\mathrm{DE}$

M E D I C I N A

T R O P I C A L

$\mathrm{DE}$

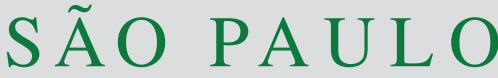

JOURNAL OF THE SÃO PAULO INSTITUTE OF TROPICAL MEDICINE

'Universidade Federal do Ceará, Faculdade de Medicina, Departamento de Medicina Clínica, Programa de Pós-Graduação em Ciências Médicas, Fortaleza, Ceará, Brazil

${ }^{2}$ Hospital Geral de Fortaleza, Programa de Residência Médica em Nefrologia, Fortaleza, Ceará, Brazil

3Universidade de Fortaleza, Fortaleza, Ceará, Brazil

Correspondence to: Elizabeth De Francesco Daher Universidade Federal do Ceará, Faculdade de Medicina, Departamento de Medicina Clínica, Rua Vicente Linhares, 1198, CEP 60270-135, Fortaleza, CE, Brazil.

Tel: $+55853224-9725$

Fax: $+55853261-3777$

E-mail: ef.daher@uol.com.br

Received: 18 August 2019

Accepted: 1 November 2019

\section{Pancreatitis as a severe complication of leptospirosis with fatal outcome: a case report}

Pedro Eduardo Andrade de Carvalho Gomes ${ }^{\circledR 1}$, Sávio de Oliveira Brilhante ${ }^{1}$, Rachel Bezerra Carvalho², Daniel Ribeiro de Sousa ${ }^{3}$, Elizabeth De Francesco Daher ${ }^{(1)} 1$

\section{ABSTRACT}

Leptospirosis is a globally distributed zoonosis with a broad clinical spectrum. This disease mostly affects liver and kidney tissues. Other organs such as the pancreas, can be affected by leptospirosis-induced vasculitis. In addition, cardiac manifestations are common, and the presence of transient ECG abnormalities can be found in $70 \%$ of the patients. We report a male patient who presented with an atypical leptospirosis that progressed with severe acute pancreatitis, acute kidney injury and atrial fibrillation. Early diagnosis and adequate supportive therapy are crucial for the appropriated management of symptoms.

KEYWORDS: Leptospirosis. Arrhythmia. Acute pancreatitis. Acute kidney injury.

\section{INTRODUCTION}

Leptospirosis is a globally spread zoonosis with a broad clinical spectrum. It is caused by pathogenic spirochetes of the genus Leptospira transmitted to humans mainly by contact with the urine of infected mammals, most often rats ${ }^{1}$. It is associated with occupational and recreational exposure, especially in endemic areas after floods or during rainy periods ${ }^{2}$.

A wide variety of clinical presentations can occur, and numerous diseases can mimic different stages of leptospirosis. The clinical picture ranges from a mild influenza-like infection to severe illness complicated by acute kidney injury (AKI), jaundice, pulmonary hemorrhage (Weil's syndrome), myocarditis and liver failure ${ }^{1,3}$. Patients with severe leptospirosis may present with hemodynamic changes secondary to hypovolemia caused by dehydration and direct effects of toxins that impair both, the vascular endothelium and the permeability ${ }^{1}$. Mortality remains high, although it has declined in recent decades, mainly due to improvements in treatment and medical education programs ${ }^{3}$.

Leptospirosis usually affects liver and kidney tissues. It rarely affects other organs, such as the brain, pancreas, lungs, heart, gallbladder and ocular tissues. This infrequent involvement occurs mainly when vasculitis is present $t^{4,5}$.

As a matter of fact, pancreatitis is not a common complication of the disease. Vasculitis and endothelial damage are the main mechanisms to cause damage to the pancreas, leading to a variety of clinical manifestations that range from a selflimited form of the disease to a fatal condition ${ }^{6,7}$.

Diagnosis is based on clinical signs and symptoms and epidemiological data. The presence of hypokalemia is an early and characteristic finding of leptospirosis. Isolation of Leptospira provides the definitive diagnosis, although requiring a long 
period of culture. The most commonly used laboratory method for diagnosis is the microscopic agglutination test (MAT), performed with two blood samples collected two weeks apart. The test is positive when the antibody titers are four times higher than the reference ${ }^{1}$.

In the present case, we report a male patient who presented with an atypical progression of leptospirosis with severe acute pancreatitis and cardiac disturbances (atrial fibrillation) resulting in a poor outcome.

\section{CASE REPORT}

A 48-year-old unemployed man from Fortaleza, Brazil, was admitted to an intensive care unit with diffuse abdominal pain that began 10 days earlier and worsened in the previous two days, in addition to vomiting, myalgia, calf pain, fever and conjunctival hyperemia. He also presented with progressive jaundice for four days. The patient also reported dark brown urine and no stool color changes. He informed to have been bitten by a rat two weeks before admission. On physical examination, the man presented with a facial expression of pain, diminished turgor, pallor and jaundice. He was afebrile and his abdomen was enlarged, distended and painful to superficial and deep palpation. No organ enlargements were detected. Cardiac and pulmonary auscultation were normal. Blood pressure was $100 / 60 \mathrm{mmHg}$, heart rate was $116 \mathrm{bpm}$, temperature was $36.4{ }^{\circ} \mathrm{C}$, respiratory rate was $17 \mathrm{ipm}$ and oxygen saturation was $97 \%$.

Laboratory findings (Table 1) on hospital admission included hemoglobin: $12.8 \mathrm{mg} / \mathrm{dL}$, hematocrit: $36.9 \%$, leucocytes: $20,200 / \mathrm{mm}^{3}$ (with $9 \%$ of bands), platelets: 32,000/ $\mathrm{mm}^{3}$, creatinine: $2.73 \mathrm{mg} / \mathrm{dL}$, urea: $105 \mathrm{mg} / \mathrm{dL}$, lipase: $114 \mathrm{IU} / \mathrm{L}$, amylase: $664 \mathrm{IU} / \mathrm{L}$, alkaline phosphatase: $115 \mathrm{IU} / \mathrm{L}$, gamma-glutamyl transferase (GGT): $84 \mathrm{IU} / \mathrm{L}$, aspartate transaminase (AST): $96 \mathrm{IU} / \mathrm{L}$, and alanine transaminase (ALT): $81 \mathrm{IU} / \mathrm{L}$. Moreover, an abdominal ultrasound revealed enlarged liver with irregular walls and grade II steatosis; bile duct stones; normal choledochal duct and a stone in the right kidney.On the second day at the Emergency Care Unit, the patient reported persistence of the symptoms and presented with jaundice. He has also became anuric. Physical examination findings were: blood pressure: 100/60 $\mathrm{mmHg}$, heart rate: $110 \mathrm{bpm}$, respiratory rate: $17 \mathrm{ipm}$, temperature: $35.7^{\circ} \mathrm{C}$, and oxygen saturation: $93 \%$ (Table 2). Laboratory exams revealed:

Table 1 - Laboratory findings during hospital stay.

\begin{tabular}{lcccc}
\hline Hospital stay (day) & 1 & 2 & 3 & 4 \\
\hline Hemoglobin (mg/dL) & 12.8 & 11.9 & 13.2 & 13.3 \\
White Blood Cells Count (/mm³) & 20,200 & 14,800 & 33,100 & - \\
Lymphocytes (\%) & $5 \%$ & $5 \%$ & - & - \\
Total Neutrophils (\%) & $91 \%$ & $91 \%$ & - & - \\
Bands (\%) & $9 \%$ & $9 \%$ & - & - \\
Segmented Neutrophils (\%) & $82 \%$ & $88 \%$ & - & 27,000 \\
Platelets (/mm3) & 32,000 & 20,000 & 14,000 & - \\
INR & - & 1.08 & 1.09 & 1,23 \\
aPTT time & & 1,43 & 1,23 & - \\
Creatinin (mg/dL) & 2.73 & 4.1 & 6.1 & 3.1 \\
Urea (mg/dL) & 105 & 176 & 168 & 1,912 \\
Potassium (mEq/L) & - & 4.5 & 3.1 & 4,277 \\
Amylase (IU/L) & 664 & - & - & - \\
Lipase (IU/L) & 114 & - & - & - \\
Total Bilirubin (mg/dL) & - & 18.48 & - & 148 \\
Direct Bilirrubin (mg/dL) & - & 16.67 & - & 78 \\
AST (IU/L) & 96 & 77 & - & 192 \\
ALT (IU/L) & 81 & 62 & - & 81 \\
Alkaline Phosphatase (IU/L) & 115 & - & - & \\
$\gamma$ GT (IU/L) & 84 & - & - & \\
\hline
\end{tabular}

INR: International Normalised Ratio; apTT time: activated partial thromboplastin time; AST: aspartate transaminase; ALT: alanine transaminase; GGT: gamma-glutamyl transferase. 
Table 2 - Variation of vital signs during hospitalization.

\begin{tabular}{lcccc}
\hline Hospital stay (day) & 1 & 2 & 3 & 4 \\
\hline Systolic Arterial Pressure (mmHg) & $74-100$ & $84-100$ & $86-120$ & $88-151$ \\
Diastolic Arterial Pressure (mmHg) & $41-60$ & $60-60$ & $58-65$ & $79-91$ \\
Heart Rate (bpm) & $111-116$ & $64-110$ & $138-183$ & - \\
Respiratory Rate (ipm) & $17-18$ & $17-22$ & $35.0-35.8$ & $36.0-36.1$ \\
Temperature $\left({ }^{\circ} \mathrm{C}\right)$ & $34.6-36.4$ & $35.0-35.8$ & $98-100$ & $100-100$ \\
Oxygen Saturation (\%) & $97-97$ & $93-100$ & & - \\
\hline
\end{tabular}

$\mathrm{mmHg}$ : millimeters of mercury; bpm: beats per minute; imp: incursions per minute.

hemoglobin: $11.9 \mathrm{mg} / \mathrm{dL}$, hematocrit: $33.7 \%$, leukocytes: $14,800 / \mathrm{mm}^{3}$ (with $9 \%$ of bands), platelets: $20,000 / \mathrm{mm}^{3}$, international normalized ratio (INR): 1.08 , ratio of activated partial thromboplastin time (aPTT): 1.43 , total bilirubin: 18.48 IU/L, direct bilirubin: $16.67 \mathrm{IU} / \mathrm{L}$, indirect bilirubin: $1.81 \mathrm{IU} / \mathrm{L}$, creatinine: $4.1 \mathrm{mg} / \mathrm{dL}$, urea: $176 \mathrm{mg} / \mathrm{dL}$, sodium: $142 \mathrm{mEq} / \mathrm{L}$, potassium: $4.5 \mathrm{mEq} / \mathrm{L}, \mathrm{AST}$ : $77 \mathrm{IU} / \mathrm{L}, \mathrm{ALT}$ : $62 \mathrm{IU} / \mathrm{L}$ and the arterial blood gas showed a metabolic acidosis (pH: 7.11, $\mathrm{pCO}_{2}: 28 \mathrm{mmHg} \mathrm{pHCO}_{3}^{-}: 9.8 \mathrm{mmHg}$ ).

The antibiotic treatment (ampicillin and sulbactam), hydration, and supportive measures began and on the third day of hospitalization, the patient was transferred to a reference hospital for high complexity to perform sustained low efficiency dialysis (SLED). The continuous renal replacement therapy (CRRT) was not performed due to the unavailability of this type of therapy in the hospital. Later, on the same day, the patient progressed with respiratory distress, presenting with universal vesicular murmur with bibasal rales. He had worsening renal function, metabolic acidosis, pulmonary congestion, low platelet count $\left(14,000 / \mathrm{mm}^{3}\right)$ and persistence of anuria. Noradrenaline, platelet transfusion, ceftriaxone ( $1 \mathrm{~g}$ intravenously every $12 \mathrm{~h}$ ) and new supportive measures were initiated.

On physical examination, pulmonary and abdominal abnormalities persisted, as well as the previous symptoms (dyspnea, jaundice, myalgia and calf pain). He did not report nausea, vomiting, sweating and chills. As the patient had progressive respiratory distress and hypotension, orotracheal intubation was performed as well as an extra SLED session and volume restriction was initiated due to an oliguric acute renal injury and suspected alveolar hemorrhage. The patient's chest x-ray is shown in Figure 1. The patient has also presented with hypokalemia, which was corrected by a potassium chloride administration. Later on the same day, an electrocardiogram (ECG) was performed, revealing atrial fibrillation (Figure 2).

On the fourth day, another SLED session was performed, even though the patient still had hemodynamic instability, and the dose of noradrenaline was increased. In addition,

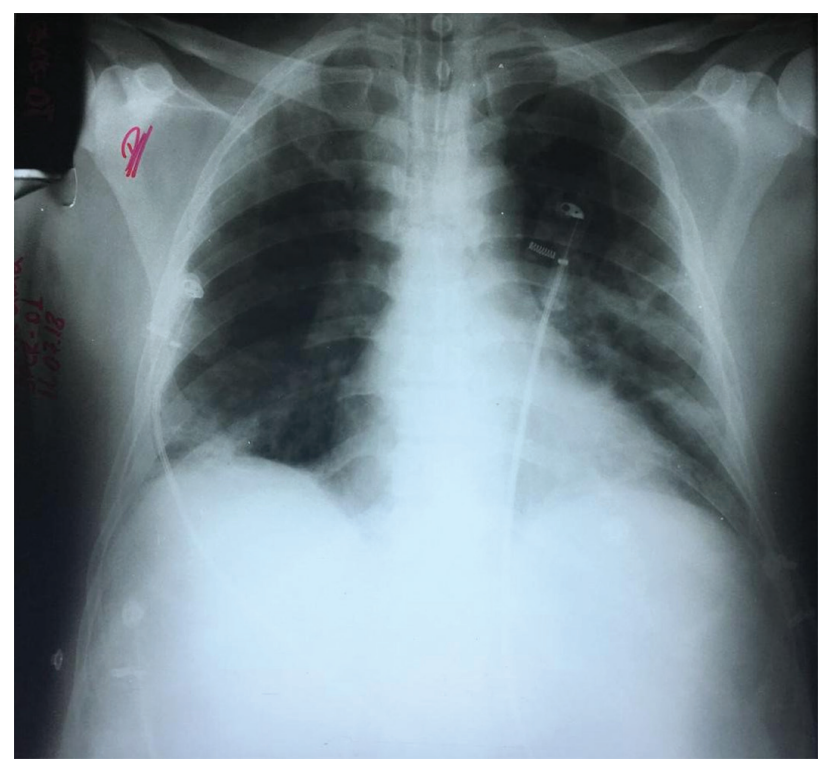

Figure 1 - Chest x-ray taken on the third day of hospitalization showing areas of confluent peribronchial consolidation.

new laboratory findings included positive tests for antiHBS and anti-HCV, but negative for VDRL, HbsAg and HIV. The levels of amylase and lipase were 1,912 IU/L and 4,277 IU/L, respectively, corroborating the diagnosis of acute pancreatitis.

Despite sustained supportive measures, the prognosis was rather poor. A few hours later, the patient presented with worsening of symptoms and had no response to vasoactive drugs, dying after four days of hospitalization.

\section{DISCUSSION}

Leptospirosis is a zoonotic disease caused by more than 250 serovars of Leptospira spp., a spirochete spread worldwide, mainly in tropical areas ${ }^{1}$. A significant number of patients are asymptomatic ${ }^{8}$. Amongst individuals with symptomatic disease, the majority presents with a mild, self-limited febrile illness, in which headache, myalgia and conjunctival suffusion may be related ${ }^{8,9}$. Other patients present with a more severe form of leptospirosis, known 


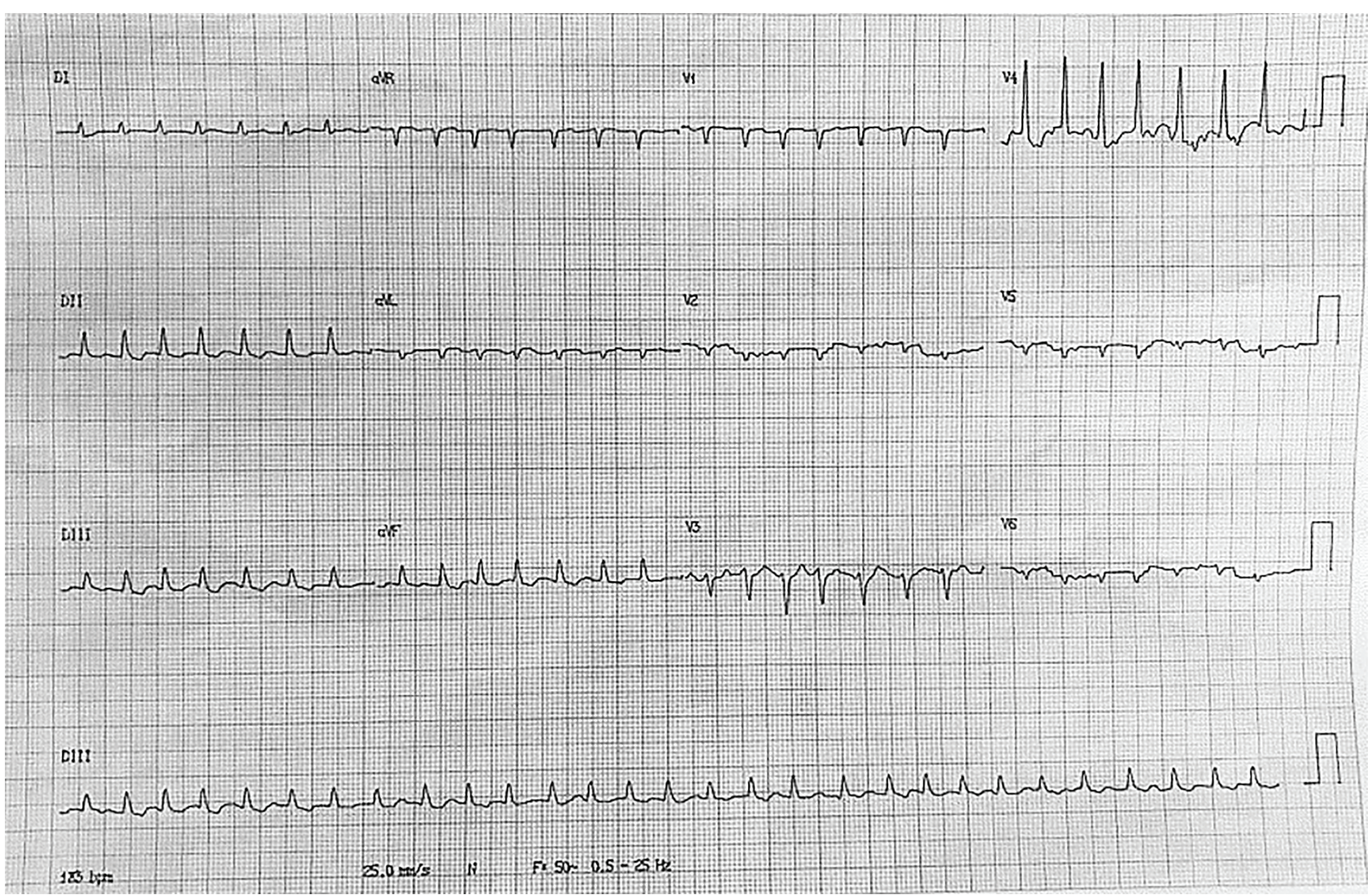

Figure 2 - Atrial fibrillation present on the ECG.

as Weil's syndrome ${ }^{6,8}$. In the reported case, the diagnosis of this condition was based on clinical manifestations associated with history of contact with animals and favorable epidemiological factors in the region.

Weil's syndrome is a multiple organ dysfunction characterized by the development of vasculitis, endothelial damage and inflammatory infiltration presenting with as jaundice, renal failure and hemorrhage. This disease mostly affects liver and kidney tissues. Other organs, such as the pancreas may be affected due to vasculitis. For the diagnosis of acute pancreatitis, a simultaneous determination of both, amylase and lipase is recommended in the evaluation of patients with abdominal pain $^{7,9-12}$. Moreover, our patient presented with a severe form of pancreatitis according to Atlanta criteria as he had persistent organ failure.

Although the mechanisms thought to cause acute pancreatitis in leptospirosis are not fully elucidated, Tolllike receptor 2 activation may play an important role on the inflammatory phenomena ${ }^{13}$. Vasculitis and endothelial damage can cause damage to the pancreas, mainly due to decreased removal of reactive oxygen waste, intracellular enzymes and toxins, and to the higher stasis of harmful elements ${ }^{14,15}$. Most cases of pancreatitis due to leptospirosis are self-limited, but some of them are associated with fatal outcomes ${ }^{6}$.
Hyperamylasemia is found in many patients with leptospirosis, which may be associated with renal failure, especially when the creatinine clearance is less than $50 \mathrm{~mL} / \mathrm{min}^{6,7,10,12}$.

In addition, the presence of transient ECG abnormalities are found in $70 \%$ of the patients but are rarely noticed at the beginning of the disease. It is possibly caused by the effect of Leptospira or the febrile illness combined with metabolic and electrolyte abnormalities ${ }^{1,3,7,8,16}$. Even though cardiac manifestations are usually not fatal, and cardiac involvement in leptospirosis tends to predict a poor prognosis e of the disease $^{16,17}$.

ECG changes include sinus tachycardia, supraventricular extra-systoles, atrioventricular block and atrial fibrillation, the most common form of arrhythmia in patients with leptospirosis ${ }^{16,18}$.

There is not a specific therapeutical approach to prevent or treat this cardiac lesions in the progression of leptospirosis. Clinical observation, ECG monitoring and supportive therapy are the main management procedures, preventing progression of subclinical conditions to a fatal outcome $\mathrm{e}^{16,19}$.

Moreover, the patient also presented a hemorrhagic manifestation, which is common among individuals with the Weil's syndrome. In this context, a retrospective study 
conducted by Daher et al. ${ }^{18}$ with 201 patients diagnosed with leptospirosis revealed that bleeding disorders were present in $35.8 \%$ of them. In the same study, death occurred in $15.4 \%$ of the patients, with pulmonary hemorrhage being the main cause of fatal outcomes. Spichler et al. ${ }^{17}$ have also indicated the pulmonary involvement as the strongest risk factor for death in patients with leptospirosis. Thus, patients with severe disease should be carefully monitored to allow proper intervention ${ }^{20}$.

\section{CONCLUSION}

Pancreatitis and atrial fibrillation can be found in the severe form of leptospirosis associated with pulmonary hemorrhage. Leptospirosis should also be considered in the differential diagnosis of obstructive jaundice in endemic areas of leptospirosis. Early diagnosis and appropriate treatment are essential to saving lives.

\section{ACKNOWLEDGMENTS}

We are very grateful to the team of attendant physicians, residents, medical students and nurses from the Hospital Geral de Fortaleza for the assistance provided to patients and for the technical support for the development of this research. This research was supported by Conselho Nacional de Desenvolvimento Científico e Tecnológico CNPq (Brazilian Research Council).

\section{CONFLICT OF INTERESTS}

The authors declare no conflict of interests.

\section{FUNDING}

This study was supported by the Conselho Nacional de Desenvolvimento Científico e Tecnológico, Brazil, grant $\mathrm{N}^{\circ}$ 405963/2016-5.

\section{REFERENCES}

1. Daher EF, Abreu KL, Silva Junior GB. Leptospirosis-associated acute kidney injury. J Bras Nefrol. 2010;32:400-7.

2. Narita M, Fujitani S, Haake DA, Paterson DL. Leptospirosis after recreational exposure to water in the Yaeyama Islands, Japan. Am J Trop Med Hyg. 2005;73:652-6.

3. Daher EF, Carvalho GS, Soares DS, Mendes MH, Parente Filho SL, Rocha HA, et al. Changing patterns in leptospirosis: a three-decade study in Brazil. Int J Infect Dis. 2017;60:4-10.

4. Farr RW. Leptospirosis. Clin Infect Dis. 1995;21:1-6.
5. Levett PN. Leptospirosis. Clin Microbiol Rev. 2001;14:296-326.

6. Rajapakse S, Rodrigo C, Balaji K, Fernando SD. Atypical manifestations of leptospirosis. Trans R Soc Trop Med Hyg. 2015;109:294-302.

7. Daher EF, Brunetta DM, Silva Junior GB, Puster RA, Patrocínio RM. Pancreatic involvement in fatal human leptospirosis: clinical and histopathological features. Rev Inst Med Trop Sao Paulo. 2003;45:307-13.

8. Daher EF, Silva Junior GB, Silveira CO, Falcão FS, Alves MP, Mota JA, et al. Factors associated with thrombocytopenia in severe leptospirosis (Weil's disease). Clinics (Sao Paulo). 2014;69:106-10.

9. Yew KL, San Go C, Razali F. Pancreatitis and myopericarditis complication in leptospirosis infection. J Formos Med Assoc. 2015;114:785-6.

10. Daher EF, Soares DS, Fernandes AT, Girão MM, Sidrim PR, Pereira ED, et al. Risk factors for intensive care unit admission in patients with severe leptospirosis: a comparative study according to patients' severity. BMC Infect Dis. 2016;16:40.

11. Kaya E, Dervisoglu A, Eroglu C, Polat C, Sunbul M, Ozkan K. Acute pancreatitis caused by leptospirosis: report of two cases. World J Gastroenterol. 2005;11:4447-9.

12. Herath NJ, Kamburapola CJ, Agampodi SB. Severe leptospirosis and pancreatitis; a case series from a leptospirosis outbreak in Anuradhapura district, Sri Lanka. BMC Infect Dis. 2016;16:644.

13. Rawla P, Bandaru SS, Vellipuram AR. Review of infectious etiology of acute pancreatitis. Gastroenterology Res. 2017;10:153-8.

14. Lane AB, Dore MM. Leptospirosis: a clinical review of evidence based diagnosis, treatment and prevention. World J Clin Infect Dis. 2016;6:61-6

15. Mazhar M, Kao JJ, Bolger DT. A 23-year-old man with leptospirosis and acute abdominal pain. Hawaii J Med Public Health. 2016;75:291-4.

16. Soares DS, Galdino GS, Rodrigues BC, Silva Junior GB, Daher EF. Arrhythmias in leptospirosis-associated acute kidney injury: a case series. Braz J Infect Dis. 2017;21:209-10.

17. Spichler AS, Vilaça PJ, Athanazio DA, Albuquerque JO, Buzzar M, Castro B, et al. Predictors of lethality in severe leptospirosis in urban Brazil. Am J Trop Med Hyg. 2008;79:911-4.

18. Daher EF, Lima RS, Silva Junior GB, Silva EC, Karbage NN, Kataoka RS, et al. Clinical presentation of leptospirosis: a retrospective study of 201 patients in a metropolitan city of Brazil. Braz J Infect Dis. 2010;14:3-10.

19. Raj S, Rao P, Gowda R, Bhat R. Paroxysmal atrial fibrillation: an unusual association of leptospirosis. Int J Adv Med. 2014;1:46-8.

20. Helmerhorst HJ, Van Tol EN, Tuinman PR, De Vries PJ, Hartskeerl RA, Grobusch MP, et al. Severe pulmonary manifestation of leptospirosis. Neth J Med. 2012;70:215-21. 